\title{
CropSAT - a decision support system for practical use of satellite images in precision agriculture
}

\author{
Omran Alshihabi ${ }^{1}$, Kristin Piikki $^{1}$, Mats Söderström ${ }^{1}$ \\ ${ }^{1}$ Swedish University of Agricultural Sciences (SLU, Skara), Sweden \\ omran.alshihabieslu.se
}

\begin{abstract}
CropSAT is an interactive decision support system (DSS) that provides vegetation index (VI) maps from Sentinel-2 data all across the globe and lets users delineate fields, design variable-rate application of user specified inputs (mainly nitrogen, but also e.g. fungicides or growth regulators) based on the VI maps. The CropSAT DSS was initially developed in a research project at the Swedish University of Agricultural Sciences (SLU), and has since its launch in 2015 been continuously developed in a private-public-partnership between SLU, private companies and the Swedish Board of Agriculture. Now it has global coverage, is continuously updated with new satellite images, and is provided free-ofcharge in multiple languages (including Arabic and French). The present study aims at describing the CropSAT systems, summarizing research results from the ongoing developmental process and pointing to opportunities for applications in precision agriculture, e.g. in Morocco and other countries in North Africa.
\end{abstract}

Keywords: CropSAT, decision support system, Sentinel-2, precision agriculture, nitrogen fertilization.

\section{$1 \quad$ Precision nitrogen fertilization}

By better adjustment of nitrogen $(\mathrm{N})$ application to soil supply and crop demand, one can potentially increase yields and improve the quality of the produce. Well-adjusted $\mathrm{N}$ rates also means improved nitrogen use efficiency and in turn better profit and minimized risk of negative environmental impact associated with non-optimal nutrient application, such as nitrate leaching [1] and emissions of gaseous nitrous oxide [2]. Technology for variable rate application (VRA) of $\mathrm{N}$ in field crop production has been available for at least two decades. However, not only machinery is required; one also needs decision support, e.g. in the form of maps, in order to optimize $\mathrm{N}$ rates spatially across fields and to create the VRA-files that control the spreaders. The required decision support can, for example, be derived from satellite based remote sensing of current crop status at the time for fertilization.

Satellite-based crop monitoring has been one of the main uses of earth observation satellites ever since the launch of Landsat in the early 70s. For example, biomass, chlorophyll concentration and nitrogen uptake have been described by spectral indices $[3,4,5]$. There are also several satellite-based systems around the world aiming to provide decision support for VRA of $\mathrm{N}$ in field crop production (e.g. FARMSTAR or 
SOYLsense). The system described here is CropSAT [6], an interactive decision support system (DSS) that provides vegetation index (VI) maps from Sentinel-2 data all across the globe and lets users delineate fields, design VRA files of user specified inputs (mainly nitrogen, but also e.g. fungicides or growth regulators) based in the VI maps. The difference between CropSAT and similar tools is that CropSAT is free for use globally, mainly aiming at providing the users with satellite image that they easily and interactively can convert to VRA files in various formats compatible with e.g. multiple types of fertiliser spreaders. CropSAT is in practical use since 2015, mainly in Scandinavia with thousands of users, and since 2018 it has been available in a global version (www.cropsat.com).

\section{The Sentinel-2 Earth observation Mission}

The Copernicus Sentinel-2 mission (European Space Agency, EU) was designed to provide optical earth observation data for, among other purposes, applications in crop production. The two Sentinel-2 satellites orbit the Earth sun-synchronously and deliver multispectral imagery of $10 \mathrm{~m}, 20 \mathrm{~m}$, and $60 \mathrm{~m}$ spatial resolution (Table 1). In total, there are 13 wavelength bands of varying bandwidth, some of which have been specially chosen for remote sensing of vegetation, e.g. bands 6 and 7 in the so-called red edge region of crop canopy spectra. The revisit time in the beginning of the mission, when only Sentinel-2A was in operation (from 2016), was ten days at the equator, but about five days at high latitudes such as Scandinavia. With the launch of the second satellite (Sentinel-2B; available from 2017), the revisit time was halved.

Table 1. Sentinel bands with according spectral resolution, central wavelength and bandwidth for the sensors of the two Sentinel-2 satellites (S2A and S2B, respectively) (European Space Agency, EU, 2018).

\begin{tabular}{lrrrrr}
\hline Band & $\begin{array}{r}\text { Spatial } \\
\text { resolution } \\
(\mathrm{m})\end{array}$ & $\begin{array}{r}\text { S2A } \\
\text { Center } \\
(\mathrm{nm})\end{array}$ & $\begin{array}{r}\text { S2A } \\
\text { Width } \\
(\mathrm{nm})\end{array}$ & $\begin{array}{r}\text { S2B } \\
\text { Center } \\
(\mathrm{nm})\end{array}$ & $\begin{array}{r}\text { S2B } \\
\text { Width } \\
(\mathrm{nm})\end{array}$ \\
\hline 1- Coastal aerosol & 60 & 443.9 & 27 & 442.3 & 45 \\
2- Blue & 10 & 496.6 & 98 & 492.1 & 98 \\
3- Green & 10 & 560.0 & 45 & 559 & 46 \\
$4-$ Red & 10 & 664.5 & 38 & 665 & 39 \\
5- Vegetation red edge & 20 & 703.9 & 19 & 703.8 & 20 \\
6- Vegetation red edge & 20 & 740.2 & 18 & 739.1 & 18 \\
7- Vegetation red edge & 20 & 782.5 & 28 & 779.7 & 28 \\
8- NIR & 10 & 835.1 & 145 & 833 & 133 \\
8A- Narrow NIR & 20 & 864.8 & 33 & 864 & 32 \\
$9-$ Water vapour & 60 & 945 & 26 & 943.2 & 27 \\
10- SWIR - Cirrus & 60 & 1373.5 & 75 & 1376.9 & 76 \\
\hline
\end{tabular}




\begin{tabular}{llllll}
$11-$ SWIR & 20 & 1613.7 & 143 & 1610.4 & 141 \\
$12-$ SWIR & 10 & 2202.4 & 242 & 2185.7 & 238 \\
\hline
\end{tabular}

\section{The CropSAT decision support system}

\subsection{A short history}

CropSAT is a web based decision support system (DSS) that provides satellite-based vegetation index maps initially developed for the creation of VRA files for $\mathrm{N}$ fertilization. The development of CropSAT started in 2013 in a research project lead by the Swedish University of Agricultural Sciences (SLU), and was made fully functional in 2014 in collaboration with the regional development organisation Agroväst Livsmedel $\mathrm{AB}$, an advisory organisation (Hushållningssällskapet), and the private company DataVäxt AB, who currently owns the system. Further refinements were carried on in 2015 supported by the environmental Focus-on-Nutrients advisory programme (run by the Swedish Board of Agriculture), and in that year the system was launched for public use in Sweden under the name CropSAT (Fig. 1). CropSAT is currently based on Sentinel-2 data. The CropSAT system was initially based on DMC low-cost data (the UKDMC-2 satellite, DMCii Ltd, UK) with $22 \mathrm{~m}$ spatial resolution, with 30-m Landsat 8 as backup. In 2016-2017 the system was launched in other Nordic countries and in 2018 a global version was launched, available in multiple languages, including Arabic and French.

The research project, in which CropSAT was first developed, aimed at investigating the possibility of running a satellite-based DSS for VRA for supplemental fertilization of winter wheat (Triticum aestivum L.) in Sweden, a country with frequent cloud cover and it was deemed feasible, even if that first trial season was unusually cloudy. A functioning system has proven to be instrumental in promoting the application of precision agriculture (PA) in Sweden.

\subsection{How it works}

The global version of the CropSAT system follows a simple interactive workflow:

1. First, an area of interest (often a crop field) is delineated. In the Swedish version, digitized field boundaries are provided from a national database (Swedish Board of Agriculture), while in the global version, where such data are lacking, the user digitizes the area boundaries manually on the screen.

2. Then, the user is provided with a list of Sentinel-2 images available for that field. Previews becomes visible to facilitate selection of an appropriate image not afflicted with clouds or cloud shadows.

3. A vegetation index (VI) map is computed from the chosen image and the user is allowed to specify the rate of $\mathrm{N}$ fertilizer (or other product) for five intervals of the VI. 
4. A VRA map is produced and the user is provided with interactive tools to adjust it (e.g. by drawing on the map or by specifying a new mean rate).

5. The VRA map can then be exported in various file formats (for different brands of spreaders) or downloaded as a map for manual use.

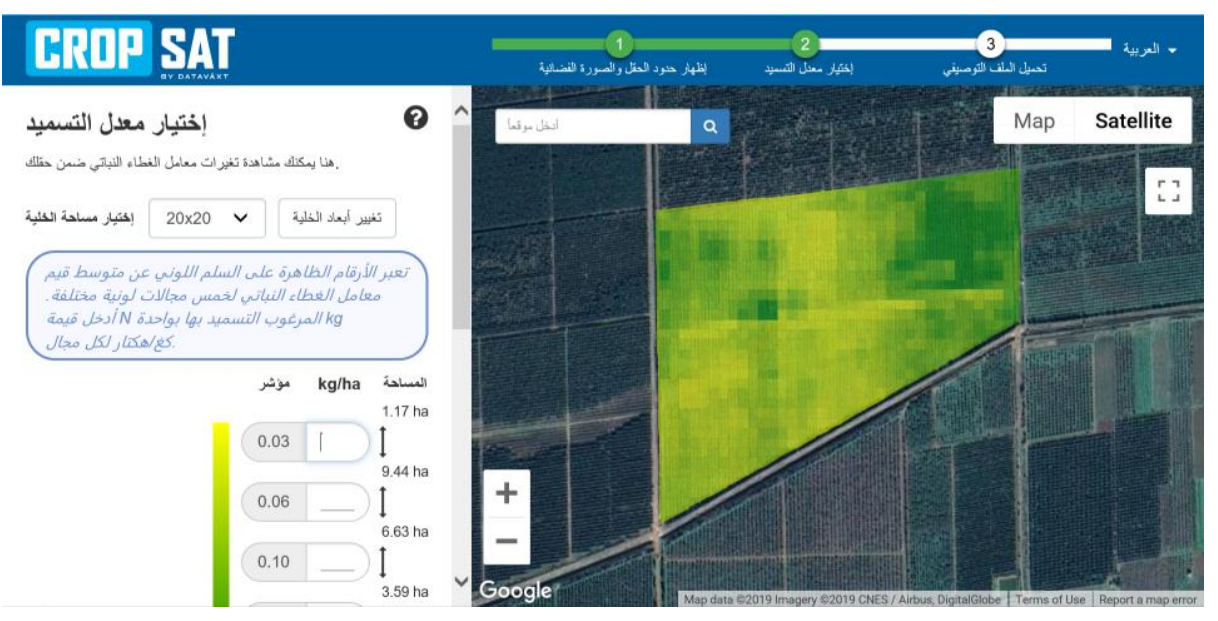

Fig. 1. Screenshot from CropSAT, showing a vegetation index map of a field near Khenichet, Morocco, May 9, 2019.

\subsection{Vegetation indices used}

Vegetation indices are used to summarize spectral information from multiple bands in one value/image. VIs are designed to correlate with, and be used as proxies for, certain crop properties, such as above ground biomass or above-ground $\mathrm{N}$ content (here referred to as $\mathrm{N}$ uptake). Since the start of CropSAT, the modified soil adjusted vegetation index 2 (MSAVI2; [7]) has been used in the system in most countries. This is because: i) it has shown fairly good correlation with $\mathrm{N}$ uptake, ii) it reduces the effect of soil reflectance early in the season, and iii) in tests it was less sensitive to saturation later in the season compared to e.g. the normalized difference vegetation index (NDVI; [6]). The latter is especially important for late supplementary fertilization to winter wheat, which in Sweden often is done around Zadok's growth stage DC37 [8].

\subsection{Implementation of $\mathrm{N}$ uptake mapping}

Winter wheat. In an effort to facilitate for the users to convert the VI maps to VRA maps of $\mathrm{N}$, work is underway to develop $\mathrm{N}$ uptake maps directly from the satellite data $[6,9]$. For winter wheat, successful models has been developed for a range of cultivars used in Sweden. A prediction model based on the chlorophyll index [10], using the Sentinel-2 bands 6 and 7, had a validation mean absolute error of around $11 \mathrm{~kg} \mathrm{~N} \mathrm{ha}^{-1}$ 
[9], and this model is now tested within the CropSAT system in Sweden (Fig. 2). Still, even if maps of $\mathrm{N}$ uptake are a useful addition to the VI maps, a remaining challenge is the transfer of these maps to real management actions such as how much $\mathrm{N}$ to apply. For example, the expected yield is necessary for estimating the required amount of $\mathrm{N}$. Currently the user is recommended to visit a few areas in the field with different map values, and make a decision within the field, e.g. using a leaf sensor such as the Yara $\mathrm{N}$-tester (Yara Gmbh, Hanninghof, Germany), which can provide an N recommendation. Earlier studies have reported successful use of satellite data and handheld chlorophyll meters in combination [11]. Alternatively, a manual judgement by the farmer or advisor is an option.

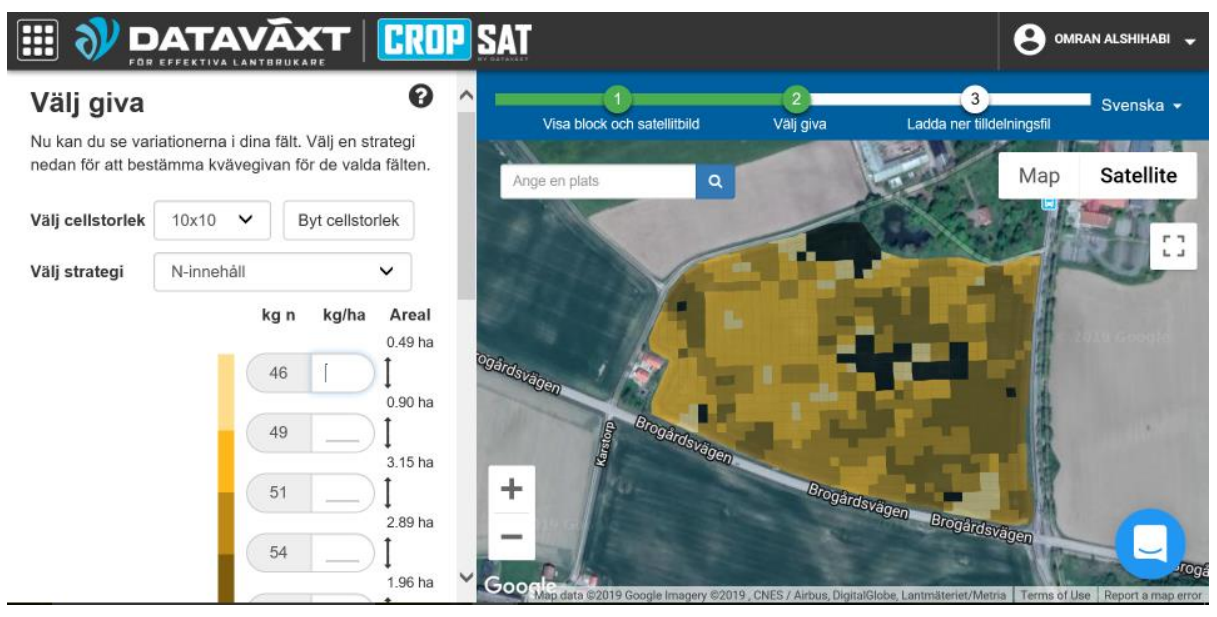

Fig. 2. $\mathrm{N}$ uptake variation map for a winter wheat field in Skara, Sweden in $\mathrm{kg} \mathrm{N}$ ha-1. The satellite image is dated May 2, 2019.

Oilseed rape. In Scandinavia, winter oilseed rape (Brassica Napus L.) is sown in late summer or early autumn. The above ground biomass wilts during winter, but when spring temperatures permit the crop continues to grow. A good estimate of $\mathrm{N}$ uptake before the winter has proved to be useful for the optimization of the $\mathrm{N}$ fertilization in the spring. Based on ongoing research at SLU, two methods for determining the $\mathrm{N}$ uptake in oilseed rape has been implemented in the Swedish version of CropSAT [12]. One method relies on manual calibration of VI maps based on biomass data obtained by cutting the crop in $1 \mathrm{~m}^{2}$ plots in 3-5 places within the field. The biomass values can be directly recalculated to $\mathrm{N}$ uptake, and the figures can be used to produce $\mathrm{N}$ uptake maps within the DSS. The other method is an absolute calibration model through which the VI map from a suitable date (in Sweden late October to early November; if later, the sun angle is too low at such high latitudes for efficient use of satellite images for assessment of crop status) can be recalculated to $\mathrm{N}$ uptake. The latter method is under development in ongoing research [12]. 


\subsection{Spatial protein content prognoses in wheat and barley}

The protein content of small-grain crops is one of the factors that determines the quality and price of the produce. It has been found that well-functioning prediction models of protein contents through remote sensing can be developed at the flowering stage (DC 69) [13]. This is too late for fertilization, but it is still of interest both for the farmer, who can use the information for planning the harvest, and for the grain industry. In a current research project, prediction models for protein content in winter and barley (Hordeum vulgare L.) have been developed and a beta version of the wheat model is implemented in CropSAT [14]. The best models so far are multivariate models using several of the Sentinel-2 bands, and the models were improved when images from DC69-73 were used in combination with images from around DC37.

\subsection{Future opportunities}

Sustainable uses of natural resources in agriculture in arid and semi-arid areas require integrated management of soil and water. Water scarcity and climate change demand scientifically based DSSs in fertilizer application and water management in the agricultural sector. In a future version of CropSAT, also VIs related to the water status (such as NDWI [15]) of the crop could be presented as decision support for variable-rate irrigation and VRA of nitrogen, so that farmers and authorities can manage their natural resources in a sustainable, profitable and practical way.

\section{Summary}

CropSAT is a satellite-based DSS for precision agriculture provided for free and with global coverage. Several research studies have been -and are being-carried out in the continuous development of the DSS. Methods have been developed for translation of VI maps to $\mathrm{N}$ uptake maps (winter wheat in Sweden), to $\mathrm{N}$ rate maps (oilseed rape in Sweden) and for spatial grain protein content predictions for harvest planning (malting barley, Sweden). The system is now widely used as a DSS for VRA of N but also for VRA of other inputs, e.g. pesticides and growth regulators. The tool supports several languages, and recently the Arabic language was included, which opens for possible further developments and dissemination in the Arab world.

\section{Acknowledgements}

CropSAT was developed in a project financed by the Swedish Foundation for Agricultural Research (SLF; project no. H1233115). Funding for 2015 and 2016 was provided by Focus-on-Nutrients (Swedish Board of Agriculture), and Agroväst Livsmedel AB. The current part of the project is funded by VGR/SLU (contract: RUN 2018-00141) together with Dataväxt $\mathrm{AB}$, Sweden. 


\section{References}

1. Delin, S., Stenberg, M.: Effect of nitrogen fertilization on nitrate leaching in relation to grain yield response on loamy sand in Sweden. European Journal of Agronomy 52, 291-296 (2014).

2. Balafoutis, A., Beck, B., Fountas, S., Vangeyte, J., Wal, T. V. D., Soto, I., et al.: Precision agriculture technologies positively contributing to GHG emissions mitigation, farm productivity and economics. Sustainability, 9(8), 1339 (2017).

3. Fernández, S., Vidal, D., Simón, E., Solé-Sugrañes, L.: Radiometric characteristics of Triticum aestivum cv, Astral under water and nitrogen stress. International Journal of Remote Sensing, 15, 1867-1884 (1994).

4. Reusch, S.: Optimisation of oblique-view remote measurement of crop N-uptake under changing irradiance conditions. In: Stafford J., Werner A. (eds.), Precision agriculture. Wageningen Academic Publishers. pp. 573-578 (2003).

5. Söderström, M., Börjesson, T., Pettersson, C.G., Nissen, K., Hagner, O.: Prediction of protein content in malting barley using proximal and remote sensing. Precision Agriculture, 11, 587-599 (2010).

6. Söderström, M., Piikki, K., Stenberg, M, Stadig, H., Martinsson, J.: Predicting nitrogen uptake in winter wheat by combining proximal crop measurements with Sentinel-2 and DMC satellite images in a decision support system for farmers. ACTA Agriculturae Scandinavica, Section B - Soil \& Plant Science, 67, 637-650 (2017).

7. Qi, J., Chehbouni, A., Huete, A.R., Kerr, Y.H.: Modified Soil Adjusted Vegetation Index (MSAVI). Remote Sensing of Environment 48, 119-126 (1994).

8. Zadok, J.C., Chang, T.T., Konzak, C.F.: A decimal code for the growth stages of cereals. Weed Res. 14, 415-421(1974).

9. Wolters S., Söderström M., Piikki K., Stenberg M.: Near-real time winter wheat N uptake from a combination of proximal and remote optical measurements: how to refine Sentinel2 satellite images for use in a precision agriculture decision support system. In: Stafford J. (ed.), Precision Agriculture '19. Wageningen Academic Publishers. pp. 1001-1007 (2019).

10. Gitelson, A.A, Gritz, Y., Merzlyak, M.N.: Relationships between leaf chlorophyll content and spectral reflectance and algorithms for non-destructive chlorophyll assessment in higher plant leaves. Journal of Plant Physiology 160, 271-282 (2003).

11. Miao, Y., Mulla, D.J., Randall, G.W., Vetsch, J.A., Vintila, R.: Combining chlorophyll meter readings and high spatial resolution remote sensing images for in-season site-specific nitrogen management of corn. Precision Agriculture. 10, 45-62 (2009).

12. Engström, L, Wetterlind, J., Söderström, M., Piikki, K., Stenberg, B.: Decision support tools for spring $\mathrm{N}$ fertilisation of winter oilseed rape - estimation of $\mathrm{N}$-uptake in late autumn using UAV. Proceedings of the 20th Nitrogen Workshop. Side event: Nutrient management and decisions support systems. Coupling C-N-P-S cycles. Renne, France. 27 June (2018).

13. Börjesson, T., Söderström, M.: Prediction of protein content in cereals using canopy reflectance. In: Stafford J., Werner A. (eds.), Precision agriculture. Wageningen Academic Publishers. pp. 89-94 (2003).

14. Börjesson, T., Wolters, S., Söderström, M.: Satellite based modelling of protein content in winter wheat and malting barley. In: Stafford J. (ed.), Precision Agriculture '19. Wageningen Academic Publishers. pp. 581-587 (2019).

15. McFeeters, S.K.: The use of normalized difference water index (NDWI) in the delineation of open water features. International Journal of Remote Sensing,17, pp.1425-1432 (1996). 